\title{
Ultrasound-guided Serratus Plane Block with Continuous Postoperative Drug Delivery System for Acute Nociceptive and Neuropathic Pain after Mastectomy. \\ Elkaradawy $\mathrm{S}^{1} \mathrm{MD}$, Elfakharany $\mathrm{M}^{1} \mathrm{MD}$, Ahmed $\mathrm{Y}^{2} \mathrm{MD}$ and Khaled $\mathrm{MA}^{3} \mathrm{MSc}$ \\ Department of anaesthesia and Pain Medicine ${ }^{1}$, Department of Surgery ${ }^{2}$, Specialist in Pharmacology and Opioid Medicine ${ }^{3}$ Medical Research Institute, University of Alexandria. Egypt
}

\section{Introduction}

Breast surgery for cancer, induces significant acute pain which may progress to persistent chronic pain in $20-80 \%$ of patients ${ }^{[1]}$. Mutlimodal analgesia controls acute post-mastectomy pain and influences positivity opioid consumption, immunological suppression and the development of chronic pain ${ }^{[2]}$. Ultrasound (US)-guided serratus plane block (SPB) and Lidocaine $5 \%$ patches (LP) were recently encouraged in management of acute and chronic postoperative pain $[2,3]$.

\section{Objectives}

The current study compared the effect of pre emptive serratus plane block ( $P$ SPPB) with postoperative drug delivery to serratus plane or around the surgica incision on acute nociceptive and neuropathic pain after mastectomy.

\section{Patients \& Methods}

The current randomized, coherent, blind study was conducted on 40 female patients with breast cancer, admitted to Medical Research Institute hospital, Alexandria University, Egypt. After taking Ethical Committee approval and patients' consents, the women assigned into two groups according to the methods of post operative analgesia. Group S: the patients received continuous delivery of bupivacaine $0.125 \%$ (CDB) $6 \mathrm{ml} / \mathrm{h}$ into serratus plane for 24 hrs postoperatively, using a $300 \mathrm{ml}$ elastomeric pump. Group $\mathrm{L}$ : received $2 \mathrm{LP}$ on the sides of surgical incision 12hrs/day for 24 hrs postoperatively. IV morphine $(3 \mathrm{mg}$ ) was given to any patient with VAS>3. Two patients in group $S$ did not complete the study as a result of slipped catheter from serratus plane and one patient developed post operative wound dehiscence. Two patients in group $L$ refused to continue with the study.

\section{Premedication}

Each patient received $0.02 \mathrm{mg} / \mathrm{kg}$ midazolam and $0.5 \mu \mathrm{g} / \mathrm{kg}$ fentanyl intravenously, to alleviate anxiety.

\section{Anaesthesia}

The surgical procedure was performed under standard general anaesthesia and US guided P-SPB. A $0.4 \mathrm{ml} / \mathrm{kg}$ bupivacaine $0.25 \%$ was used for P-SPB at the level of the $4^{\text {th }}-5^{\text {th }}$ ribs between mid and post axillary line using linear US transducer (10-12 MHz) of SonoSite machine (S nerve, 2D, Inc., USA). The adequacy of sensory block between T2T6, was confirmed before induction of anaesthesia. At the end of surgery, the surgeon inserted a 19 gauge catheter under vision between the serratus anterior and pectoralis minor muscle in patients in Group S.

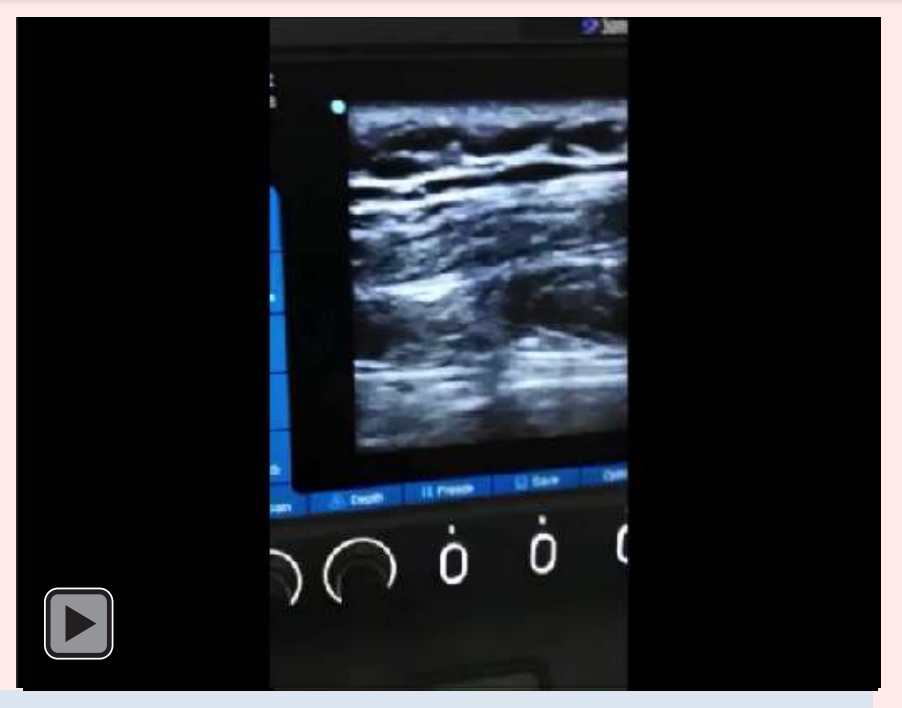

Video shows serratus plane block

\section{Measurements}

* Primary outcome evaluated acute nociceptive pain after local application of LP or CDB into serratus anterior plane. Secondary outcome measured acute neuropathic pain throughout 4 postoperative weeks., patients satisfaction and the complications for both analgesic techniques

* VAS measured nociceptive pain at rest and ipsilateral arm movement every 4 hours for 24 postoperative hours.

* DN4 questionnaire ( 10 Qs with cut-off value 4/10) was used for diagnosis of postoperative neuropathic pain

* Neuropathic Pain Scale (NPS) (10 domains scale with $0-10$ point for each domain) evaluated intensity and characters of neuropathic pain for 4 weeks postoperative.

* Sensory examination was performed on ipsilateral 2 - 6 thoracic dermatomes in comparison to the other side to detect hypothesia to blunt needle and piece of ice, hyperalgesia to pin prick and coldness and allodynia to fine touch (piece of cotton).

* The patient satisfaction questionnaire (0-4point) assessed the satisfaction with medical care and methods of postoperative analgesia.

\section{Results}

Patients' characteristics and length of operation were comparable in both studied groups.

The visual analogue scale for pain at rest and movement did not differ significantly between the studied groups Fig (1).

DN questionnaire measured similar proportions of postoperative neuropathic pain among patients in both studied groups. Table I.
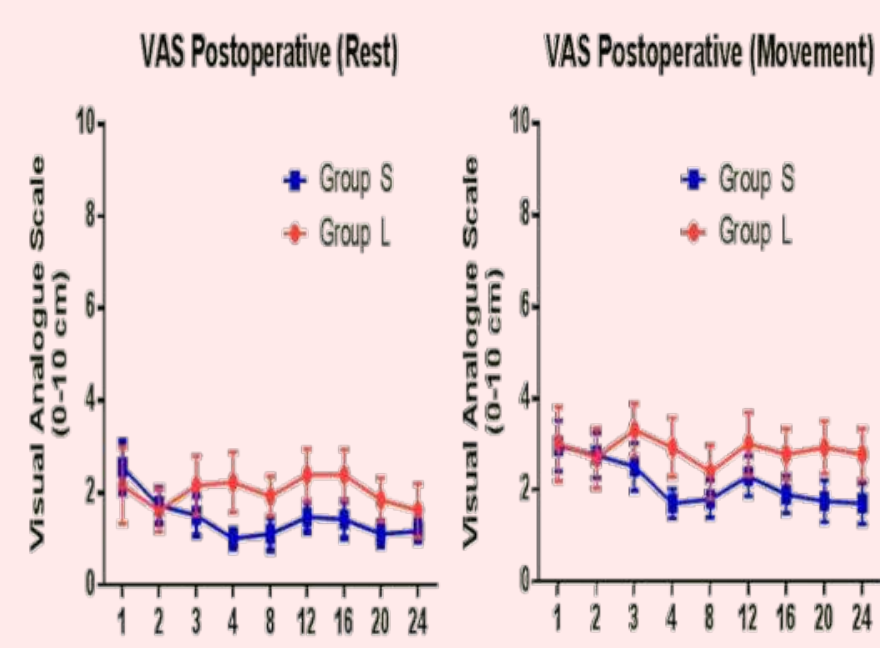

$$
\text { Time Postoperative (hours) }
$$

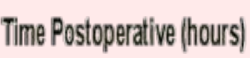

Fig.1 Visual analogue scale for pain at rest and movement 24 hrs postoperatively

The distribution of acute post-mastectomy neuropathic pain including the onset, duration and site did not show significant differences between the two studied groups. Neuropathic pain influenced work, sleep and mood comparably in both groups Table I

Table I: The diagnosis of neuropathic pain, site, onset, and duration throughout 4 weeks after Mastectomy

\begin{tabular}{|c|c|c|c|}
\hline \multicolumn{1}{|c|}{ Variables } & $\begin{array}{c}\text { Group S } \\
\mathrm{n}(17)\end{array}$ & $\begin{array}{c}\text { Group L } \\
\mathrm{N}(18)\end{array}$ & $\mathrm{p}$ \\
\hline $\begin{array}{c}\text { The number of patients reported } \\
\text { neuropathic pain ( DN } \geq 4 \text { points) }\end{array}$ & & & \\
\hline
\end{tabular}

(n) $(\%)$

$$
\begin{aligned}
& \text { week1 } \\
& \text { Week2 } \\
& \text { Week3 } \\
& \text { Week4 }
\end{aligned}
$$

Onset of neuropathic pain

(days)(Med)(min-max)

Duration of neuropathic

pain(min) (Med)(min-max) Ipsilateral site of neuropathic

pain

(n) $(\%)$ :

\section{Breast}

Axilla

Arm

Interference with

Work (n) $(\%)$

Sleep

Mood

Values a
(range)

The neuropathic pain scale (pain unpleasantness and pain intensity) showed no significant differences between the two studied groups The most frequent neuropathic pain characters were numbness, dull aching and sharpness in both groups. Table.Il

Table II: The Neuropathic Pain scale (NPS) $(0-10 \mathrm{~cm})$ in both studied groups

\begin{tabular}{|l|c|c|c|}
\hline \multicolumn{1}{|c|}{ Variable } & $\begin{array}{c}\text { Group S } \\
\mathrm{n}(17)\end{array}$ & $\begin{array}{c}\text { Group L } \\
\mathrm{n}(18)\end{array}$ & $\mathrm{P}$ \\
\hline Unpleasantness & & & \\
Week 1 & $2.5(0-5)$ & $2(0-5)$ & .463 \\
Week2 & $4(2-5)$ & $3(2-5)$ & .573 \\
Week 3 & $3(0-9)$ & $3((0-6)$ & .799 \\
Week 4 & $2(0-5)$ & $2(0-5)$ & .555 \\
Visual analogue & & & \\
Scale & & & \\
Week 1 & $4(0-5)$ & $3(0-4)$ & .144 \\
Week2 & $4.5(0-8)$ & $3(0-7)$ & .803 \\
Week 3 & $4(2-6)$ & $3((2-6)$ & .452 \\
Week 4 & $4(2-6)$ & $4(2-8)$ & .740 \\
Numbness & & & \\
Week 1 & $2(0-4)$ & $3(0-5)$ & .185 \\
Week2 & $3(0-5)$ & $3(0-6)$ & .733 \\
Week 3 & $4.5(2-5)$ & $3(2-5)^{*}$ & .022 \\
Week 4 & $3(0-5)$ & $3(2-5)$ & .668 \\
Dullness & & & \\
Week 1 & $0(0-3)$ & $0(0-4)$ & .386 \\
Week2 & $1.5(0-3)$ & $2(0-3)$ & .166 \\
Week 3 & $2(0-4)$ & $2(0-4)$ & .931 \\
Week 4 & $0(0-6)$ & $3(0-4)$ & .286 \\
Sharpness & & & \\
Week 1 & $0(0-4)$ & $0(0-5)$ & .128 \\
Week2 & $0(0-4)$ & $0(0-5)$ & .119 \\
Week 3 & $1.5(0-4)$ & $0(0-4)$ & .414 \\
Week 4 & $0(0-4)$ & $0(0-4)$ & .581 \\
\hline
\end{tabular}

$P \leq 0.05$ for Mann Whitney was considered statistically significant. Values expressed as median (range)
The intensity of numbness and painassociated lifting heavy object were significantly less in group $L$ than group $S$ at the third postoperative week. Patients' satisfaction scale with medical care and methods of pain relief was higher in Group L Table II\&II

Hypothesia to touch and coldness at the ipsilateral 2-6 thoracic dermatomes were the most frequent neuropathic pain signs encountered during sensory examination. There were no significant differences in sensory examination between the studied groups Table IV

\begin{tabular}{|c|c|c|c|}
\hline Variables & $\begin{array}{l}\text { Group S } \\
n(17)\end{array}$ & $\begin{array}{c}\text { Group L } \\
n(18)\end{array}$ & $\mathrm{p}$ \\
\hline $\begin{array}{l}\text { Precipitating factors for } \\
\text { neuropathic pain at week } 3 \\
\text { after mastectomy (0-4 points) }\end{array}$ & & & \\
\hline physical activities & $2(0-3)$ & $0(0-3)$ & 0.069 \\
\hline lifting heavy objects & $2(0-3)$ & $0(0-1)^{*}$ & 0.007 \\
\hline Hotness & $0(0-0)$ & $0(0-3)$ & 0.236 \\
\hline Coldness & $0(0-0)$ & $0(0-1)$ & 0.792 \\
\hline $\begin{array}{l}\text { Patients' satisfaction score } \\
\text { (0-4 points) }\end{array}$ & $10(10-12)$ & $10(10-12)^{*}$ & 031 \\
\hline
\end{tabular}

Table :Ill Precipitating factors for neuropathic pain and patients' satisfaction with medical care and methods of postoperative analgesia.

Table IV : The neuropathic pain signs at different thoracic dermatomes throughout 4 weeks after Mastectomy.

\begin{tabular}{|l|c|c|c|}
\hline \multicolumn{1}{|c|}{ Site } & $\begin{array}{c}\text { Group S } \\
\mathrm{N}(\%)\end{array}$ & $\begin{array}{c}\text { Group L } \\
\mathrm{N}(\%)\end{array}$ & p value \\
\hline $\begin{array}{l}\text { Anterior and posterior } \\
\text { chest wall (Th3-6)(n)(\%) }\end{array}$ & & & \\
Hyperalgesia to pin prick & $2(11.8 \%)$ & $3(16.7 \%)$ & 0.679 \\
Hyperalgesia to coldness & $1(5.9 \%)$ & $3(16.7 \%)$ & 0.316 \\
Hypothesia to touch & $9(52.9 \%)$ & $8(44.4)$ & 0.615 \\
Hypothesia to coldness & $8(47.1 \%)$ & $6(33.3 \%)$ & 0.407 \\
Allodynia to touch & $1(5.9 \%)$ & $2(11.1 \%)$ & 0.581 \\
Axilla and arm (Th2) & & & \\
Hyperalgesia to pin prick & $3(17.6)$ & $2(11.1 \%)$ & 0.581 \\
Hyperalgesia to coldness & $2(11.8 \%)$ & $1(5.6 \%)$ & 0.512 \\
Hypothesia to touch & $12(70.6 \%)$ & $10(55.6 \%)$ & 0.358 \\
Hypothesia to coldness & $8(47.1 \%)$ & $6(33.3 \%)$ & 0.407 \\
Allodynia to touch & $3(17.6)$ & $2(11.71 \%)$ & 0.581 \\
\hline
\end{tabular}

Values are expressed as frequencies and \% Conclusion \&Recommendations

Lidocaine $5 \%$ patches as a part of multimodal analgesia is as effective as CDB into serratus plane, in reducing nociceptive pain, more superior in reducing numbness and favoured by patients after mastectomy.

Further studies are encouraged to collect larger samples from multicenter with longer follow-up periods. 